\title{
A Study of Age-Wise Spectrum of Gastrointestinal Biopsies with Endoscopic Correlation a 5-Year Experience from a Tertiary Health Care Centre in North India
}

\author{
Bushra Siddiqui', Shahbaz Habib Faridi ${ }^{2}$, Durre Shehwar ${ }^{3 *}$, Saqib Ahmed ${ }^{4}$ and Mastakim Ahmed \\ Mazumder 5
}

\author{
${ }^{1}$ Assistant Professor, Department of Pathology, Jawaharlal Nehru Medical College, AMU, India \\ ${ }^{2}$ Assistant Professor, Department of Surgery, Jawaharlal Nehru Medical College, AMU, India \\ ${ }^{3}$ Senior Resident, Department of Pathology, Gauhati Medical College, India \\ ${ }^{4}$ Junior Resident, Department of Pathology, Jawaharlal Nehru Medical College, AMU, India \\ ${ }^{5}$ Senior Resident, Department of Medicine, Jawaharlal Nehru Medical College, AMU, India
}

*Corresponding author: Dr. Durre Shehwar, Department of Pathology, Gauhati Medical College and Hospital, Guwahati, Assam, 781032, India, Tel: $+91-980-8680-031$

\begin{abstract}
Endoscopic biopsy is a common procedure performed in the hospital for a variety of benign and malignant lesions of gastrointestinal tract. Endoscopy is incomplete without biopsy and histopathology is the gold standard for the diagnosis of endoscopically detected lesions. This study aims at analysing age-wise spectrum of gastrointestinal biopsies with their endoscopic correlation. A total of 556 endoscopic biopsy specimens from upper and lower gastrointestinal tract were studied retrospectively from January 2014 to October 2019 in the department of pathology, Jawaharlal Nehru Medical College (JNMC) Aligarh Muslim University, Aligarh. Biopsies were retrieved using flexible fibre-optic endoscope and also video endoscope. Out of 556 gastrointestinal endoscopic biopsy samples, maximum numbers of cases were in the adult age group (13-59 yrs) 403 (72\%). M:F ratio in paediatric, adult, geriatric population was 1.4:1, 1.5:1, 1.6:1 respectively. Among paediatric population duodenal biopsies were maximum being 29 (44\%), most common diagnosis being celiac disease $14(22 \%)$. Among adult population maximum were stomach biopsies 190 (47\%), most common being non specific inflammation $105(26 \%)$. Among geriatric population maximum were oesophageal biopsies, most common lesion being squamous cell carcinoma 24 (28\%). Endoscopic examination and biopsy is a convenient procedure for accurate objective assessment of patients with gastrointestinal symptoms. Clinical and endoscopic findings along with histopathological correlation help in making an accurate diagnosis.
\end{abstract}

\section{Keywords}

Gastrointestinal biopsies, Histopathology, Endoscopy, Non-specific inflammation, Celiac disease, Squamous cell carcinoma

\section{Introduction}

Gastrointestinal (GI) tract extends from oesophagus to anus, and is a common site for various pathologies ranging from non-neoplastic lesions to pre-malignant and malignant lesions. Gastrointestinal disorders are most commonly encountered in clinical practice. According to GLOBOCAN 2018, gastric cancer is the $5^{\text {th }}$ most common cancer worldwide and is $3^{\text {rd }}$ most common cause of cancer related deaths [1]. Gastrointestinal cancers are associated with substantial morbidity and mortality. Early diagnosis is thus required to lessen patient suffering and improve disease outcome [2].

Gastrointestinal biopsies are the major bulk specimens received in the surgical pathology section of tertiary hospital. These include endoscopic biopsies from gastric and duodenal mucosa, appendicectomies, colonoscopic biopsies, colectomies, etc. [3]. Endoscopy and colonoscopy are minimally invasive diagnostic proce-

Citation: Siddiqui B, Faridi SH, Shehwar D, Ahmed S, Mazumder MA (2020) A Study of Age-Wise Spectrum of Gastrointestinal Biopsies with Endoscopic Correlation a 5-Year Experience from a Tertiary Health Care Centre in North India. Int J Pathol Clin Res 6:113. doi.org/10.23937/2469-5807/1510113 Accepted: October 17, 2020: Published: October 19, 2020

Copyright: (c) 2020 Siddiqui B, et al. This is an open-access article distributed under the terms of the Creative Commons Attribution License, which permits unrestricted use, distribution, and reproduction in any medium, provided the original author and source are credited. 
dures which aids in diagnosis and treatment. Endoscopic biopsies play a critical role in detecting dysplasias and early cancers, hence, aids in early management.

Endoscopic biopsies are not just of diagnostic significance, but they are also used to monitor the disease course, also aids in detecting treatment response and its complications. These are considered as the gold standard investigation for diagnosing gastrointestinal lesions [2].

\section{Aims and objective}

To study age wise distribution of GI lesions in a tertiary healthcare centre of North India, along with their clinical, endoscopic and histopathological correlation.

\section{Material and Methods}

This was a retrospective study conducted in the department of pathology, Jawaharlal Nehru Medical College (JNMC) Aligarh Muslim University, Aligarh over a period of 5 years from January 2014 to October 2019. A total of 556 endoscopic biopsies from upper and lower GI tract were evaluated during this period. Relevant clinical details were noted as required for diagnostic support. Biopsies were retrieved using flexible fibre-optic endoscope and video endoscope. They were transferred to a bottle containing $10 \%$ neutral formalin, processed and embedded. 5 micron thick sections were done and routine staining with haematoxylin and eosin was done in all the cases. Special stains such as PAS and Giemsa were applied as and when required.

In this study we propose to analyse the histopathological spectrum of gastrointestinal lesions, received in the Department of Pathology, Jawaharlal Nehru Medical College, AMU, Aligarh. Age and sex distribution of these lesions was studied along with the distribution of benign and malignant lesions with respect to age and site.

\section{Results}

The present study comprised 556 endoscopic biopsies received in the department of pathology over a period of 5 years (Table 1 ).

Out of 556 gastrointestinal endoscopic biopsy sam- ples, maximum numbers of cases were in the adult age group (13-59 yrs) 403 (72\%). This was followed by 88 cases $(16 \%)$ in geriatric population. Endoscopic biopsies in paediatric group are less comparatively (Table 2).

There was a clear male preponderance in each agegroup, with $\mathrm{M}: \mathrm{F}$ ratio in paediatric, adult and geriatric population being 1.4:1, 1.5:1 and 1.6:1 respectively (Table 3).

The incidence of upper $\mathrm{Gl}$ endoscopic biopsies was maximum in adults $(91 \%)$ followed by geriatric population (74\%). In our study, maximum numbers of lower gastrointestinal endoscopic biopsies were done in paediatric group (42\%) (Table 4).

In the present study, among GI lesions diagnosed on endoscopic biopsies benign lesions were more prevalent in all age groups. Among esophageal lesions, ma-

Table 1: Age wise distribution of gastrointestinal lesions.

\begin{tabular}{|l|l|l|}
\hline Age group (years) & $\begin{array}{l}\text { No. of } \\
\text { Cases }\end{array}$ & $\begin{array}{l}\text { Percentage } \\
\text { (\%) }\end{array}$ \\
\hline Paediatric group $(<12$ yrs) & 65 & 12 \\
\hline Adult group (13-59 yrs) & 403 & 72 \\
\hline Geriatric group (> 60 yrs) & 88 & 16 \\
\hline Total & $\mathbf{5 5 6}$ & $\mathbf{1 0 0}$ \\
\hline
\end{tabular}

Table 2: Sex distribution of gastrointestinal lesions in each group.

\begin{tabular}{|l|l|l|l|}
\hline Gender & $\begin{array}{l}\text { Paediatric } \\
\text { group }\end{array}$ & Adult group & $\begin{array}{l}\text { Geriatric } \\
\text { group }\end{array}$ \\
\hline Male & $38(58 \%)$ & $240(60 \%)$ & $55(63 \%)$ \\
\hline Female & $27(42 \%)$ & $163(40 \%)$ & $33(37 \%)$ \\
\hline M:F ratio & $1.4: 1$ & $1.5: 1$ & $1.6: 1$ \\
\hline Total & $\mathbf{6 5}$ & $\mathbf{4 0 3}$ & $\mathbf{8 8}$ \\
\hline
\end{tabular}

Table 3: Upper and lower GI endoscopic biopsies in different age-groups.

\begin{tabular}{|l|l|l|l|}
\hline Category & $\begin{array}{l}\text { Paediatric } \\
\text { group }\end{array}$ & $\begin{array}{l}\text { Adult } \\
\text { group }\end{array}$ & $\begin{array}{l}\text { Geriatric } \\
\text { group }\end{array}$ \\
\hline Upper GI cases & $38(58 \%)$ & $367(91 \%)$ & $65(74 \%)$ \\
\hline Lowe GI cases & $27(42 \%)$ & $36(9 \%)$ & $23(26 \%)$ \\
\hline Total & $\mathbf{6 5}$ & $\mathbf{4 0 3}$ & $\mathbf{8 8}$ \\
\hline
\end{tabular}

Table 4: Distribution of benign and malignant lesions in different age-groups.

\begin{tabular}{|c|c|c|c|c|c|c|}
\hline \multirow[b]{2}{*}{ Site } & \multicolumn{2}{|c|}{ Paediatric group } & \multicolumn{2}{|c|}{ Adult group } & \multicolumn{2}{|c|}{ Geriatric group } \\
\hline & Benign & Malignant & Benign & Malignant & Benign & Malignant \\
\hline Esophagus & 4 & 0 & 16 & 87 & 6 & 26 \\
\hline Stomach & 4 & 0 & 183 & 7 & 20 & 2 \\
\hline Duodenum & 30 & 0 & 74 & 0 & 11 & 0 \\
\hline Ileum & 1 & 0 & 1 & 0 & 1 & 0 \\
\hline Colon & 3 & 0 & 13 & 0 & 4 & 0 \\
\hline Rectum & 20 & 0 & 14 & 0 & 6 & 0 \\
\hline Anus & 2 & 1 & 4 & 4 & 6 & 6 \\
\hline Total & $64(98 \%)$ & $1(2 \%)$ & $305(76 \%)$ & $98(24 \%)$ & $54(61 \%)$ & $34(39 \%)$ \\
\hline
\end{tabular}


Table 5: Histopathological spectrum of upper GI endoscopic biopsies.

\begin{tabular}{|c|c|c|c|c|}
\hline Site & Histopathological Diagnosis & Paediatric group & Adult group & Geriatric group \\
\hline \multirow[t]{5}{*}{ Esophagus } & Squamous cell carcinoma (Figure 1) & $1(1.5 \%)$ & $84(21 \%)$ & $24(28 \%)$ \\
\hline & Non-specific inflammation & $2(3 \%)$ & $9(2 \%)$ & $3(3 \%)$ \\
\hline & GERD & $1(1.5 \%)$ & $7(2 \%)$ & $3(3 \%)$ \\
\hline & Adeno-squamous carcinoma & 0 & $3(1 \%)$ & $2(2 \%)$ \\
\hline & TOTAL & $4(6 \%)$ & $103(26 \%)$ & $32(36 \%)$ \\
\hline \multirow[t]{6}{*}{ Stomach } & Adenocarcinoma (Figure 2a and Figure 2b) & 0 & $3(1 \%)$ & $2(2 \%)$ \\
\hline & GIST (Figure 3) & $1(1.5 \%)$ & $4(1 \%)$ & $2(2 \%)$ \\
\hline & Non-specific inflammation (Figure $4 \mathrm{a}$ and Figure $4 \mathrm{~b}$ ) & $2(1.5 \%)$ & $105(26 \%)$ & $10(11 \%)$ \\
\hline & H. Pylori induced gastritis (Figure $5 a$ and Figure $5 b$ ) & $1(1.5 \%)$ & $57(14 \%)$ & $5(6 \%)$ \\
\hline & Chronic atrophic gastritis (Figure 6) & $1(1.5 \%)$ & $21(5 \%)$ & $3(3 \%)$ \\
\hline & TOTAL & $5(6 \%)$ & $190(47 \%)$ & $22(24 \%)$ \\
\hline \multirow[t]{6}{*}{ Duodenum } & Villous atrophy & $1(1.5 \%)$ & $7(2 \%)$ & $2(2 \%)$ \\
\hline & Non-specific inflammation & $7(11 \%)$ & $38(9 \%)$ & $4(5 \%)$ \\
\hline & Duodenal ulcer & $5(9 \%)$ & $22(5 \%)$ & $2(2 \%)$ \\
\hline & Dysplasia & $2(3 \%)$ & $4(1 \%)$ & $2(2 \%)$ \\
\hline & Celiac disease & $14(22 \%)$ & $3(1 \%)$ & $1(1 \%)$ \\
\hline & Total & $29(46.5 \%)$ & 74 (18\%) & $11(12 \%)$ \\
\hline
\end{tabular}

Table 6: Histopathological spectrum of lower GI endoscopic biopsies.

\begin{tabular}{|c|c|c|c|c|}
\hline Site & Histopathological Diagnosis & Paediatric group & Adult group & Geriatric group \\
\hline \multirow[t]{3}{*}{ Ileum } & Non-specific inflammation & $1(1.5 \%)$ & $1(0.5 \%)$ & $1(1 \%)$ \\
\hline & Adenocarcinoma (Figure 7) & $1(2 \%)$ & $1(0.5 \%)$ & $1(1 \%)$ \\
\hline & TOTAL & $2(3.5 \%)$ & $2(1 \%)$ & $2(2 \%)$ \\
\hline \multirow[t]{4}{*}{ Colon } & Tubular Adenoma & 0 & $2(0.5 \%)$ & $2(2 \%)$ \\
\hline & Lymphocytic colitis & $2(3 \%)$ & $4(1 \%)$ & $1(1 \%)$ \\
\hline & Non- specific inflammation & $1(1.5 \%)$ & $3(1 \%)$ & $2(2 \%)$ \\
\hline & TOTAL & $3(4.5 \%)$ & $9(2.5 \%)$ & $5(5 \%)$ \\
\hline \multirow[t]{6}{*}{ Rectum } & Rectal polyp (Figure $8 a$ and Figure 8b) & $13(20 \%)$ & $4(1 \%)$ & $1(1 \%)$ \\
\hline & Chronic proctitis (Figure 9) & $1(1.5 \%)$ & $4(1 \%)$ & $2(2 \%)$ \\
\hline & Inflammatory Bowel Disease (Figure 10a and Figure 10b) & $3(5 \%)$ & $7(2 \%)$ & $2(2 \%)$ \\
\hline & Solitary rectal ulcer & $1(1.5 \%)$ & $2(0.5 \%)$ & $1(1 \%)$ \\
\hline & Hirschsprung disease (Figure 11) & $2(3 \%)$ & $1(0.5 \%)$ & 0 \\
\hline & Total & $20(31 \%)$ & $18(5 \%)$ & $6(6 \%)$ \\
\hline
\end{tabular}

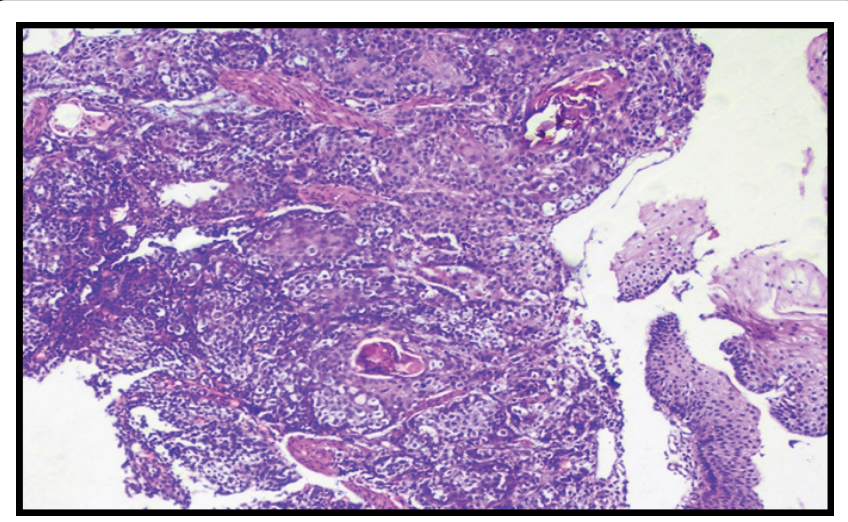

Figure 1: Squamous cell carcinoma esophagus (H\&E).

lignancies were commonly encountered in adult and geriatric population in comparison to benign lesions. In paediatric group, duodenal biopsies (30 cases out of
65) were most commonly received specimen followed by rectal-biopsies (20 cases). Gastric and duodenal biopsies constituted more than $50 \%$ of all GI endoscopic biopsies in adults. While in geriatric group, esophageal biopsies were most common endoscopic biopsy specimen received (32 out of total 88 biopsies). Among the lower $\mathrm{Gl}$ biopsies, rectal biopsies were most common in all age-groups (Table 5 and Table 6) (Figure 1, Figure $2 a$, Figure $2 b$, Figure 3, Figure 4a, Figure 4b, Figure 5a, Figure 5b, Figure 6, Figure 7, Figure 8a, Figure 8b, Figure 9, Figure 10a, Figure 10b and Figure 11).

Among the paediatric population, duodenal biopsies (29 cases, $46.5 \%$ ) were most frequent and most common diagnosis being celiac disease (14 cases, 22\%). In adults, stomach (190 cases, 47\%) was most common site of $\mathrm{Gl}$ endoscopic biopsies, and non-specific inflam- 


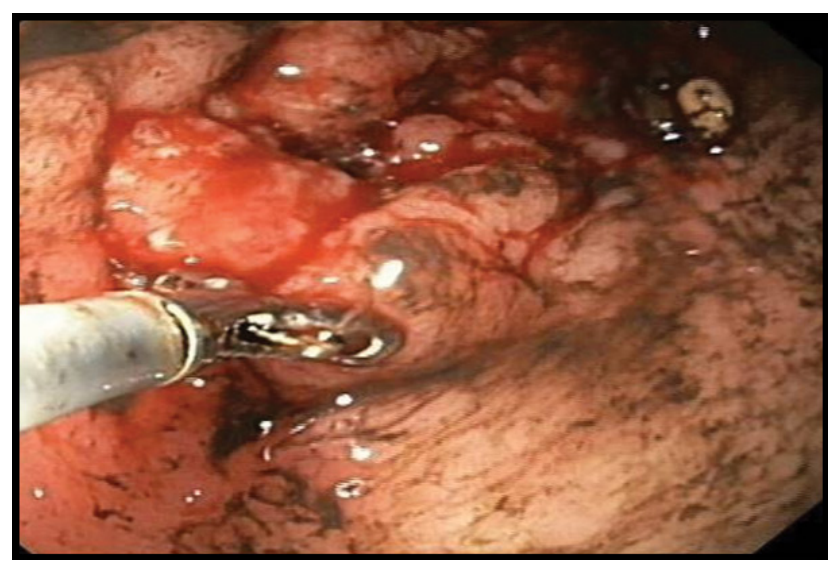

Figure 2a: Adenocarcinoma Stomach (endoscopy image).

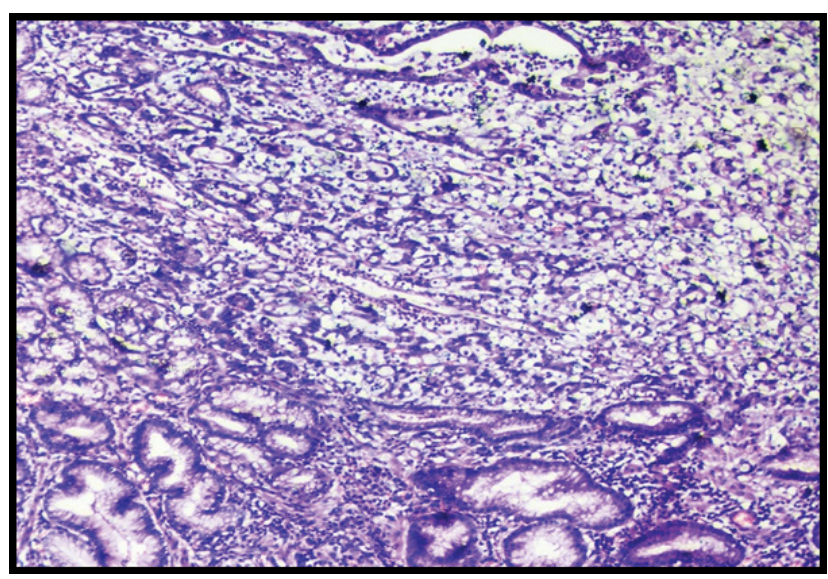

Figure 2b: Adenocarcinoma stomach (H\&E).

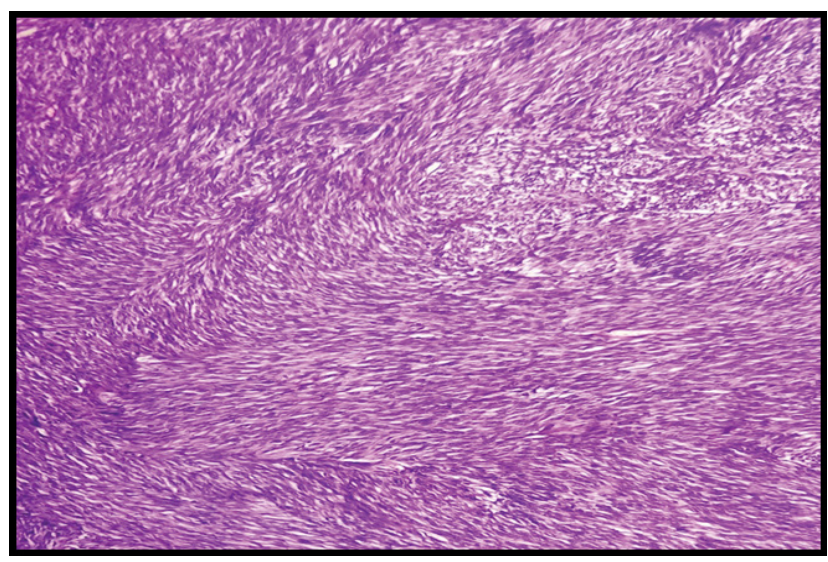

Figure 3: GIST (Gastrointestinal Stromal Tumor) (H\&E).

mation (105 cases, 26\%) was most frequent diagnosis. While, in geriatric group esophageal biopsies (32 cases, $36 \%$ ) were most common, with squamous cell carcinoma (24 cases, $28 \%$ ) being most common diagnosis made (Table 7).

\section{Discussion}

GI lesions are commonly encountered pathology in routine clinical practice. They are broadly categorised as upper and lower GI lesions based on site. Histopathological study of endoscopic biopsies plays a critical role in early detection of malignant lesions and is also used

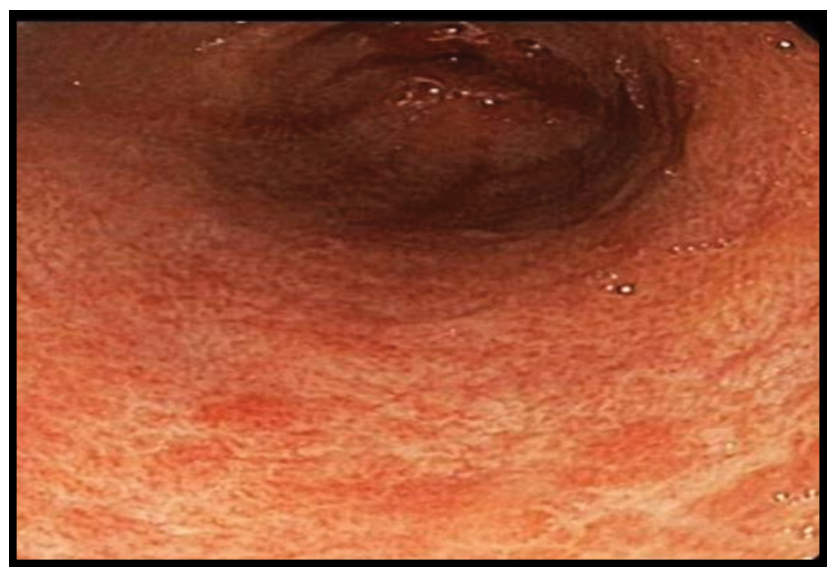

Figure 4a: Non-specific gastritis (endoscopy image).

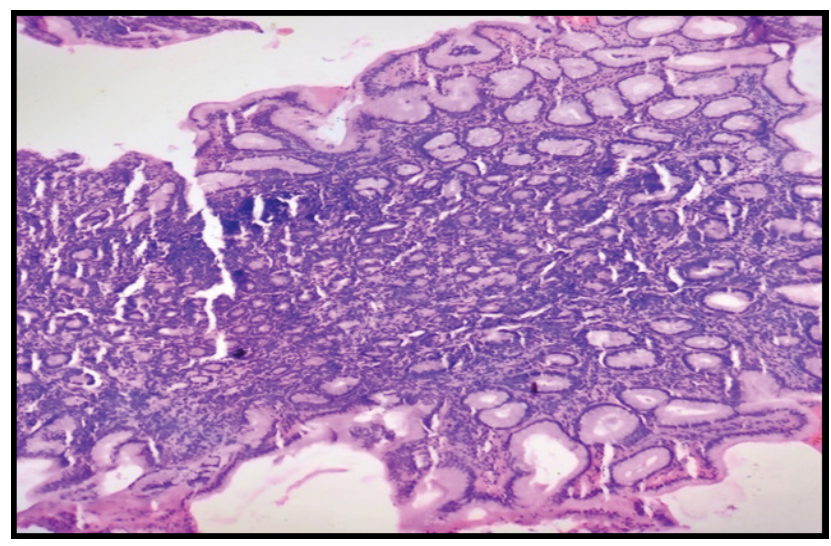

Figure 4b: Non-specific gastritis (H\&E).

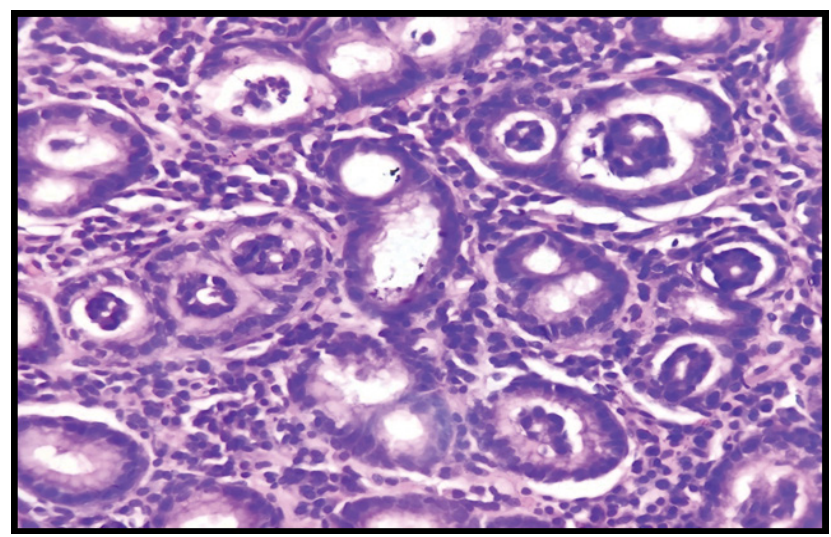

Figure 5a: H. Pylori gastritis (H\&E).

to monitor the disease course. The risk of GI malignancies increases with advancing age and increased use of endoscopic biopsies have led to early detection of these lesions. In the present study, a total of 556 endoscopic biopsies from upper and lower $\mathrm{Gl}$ tract were evaluated over the period of 5 years.

It was observed that the incidence of GI lesions was higher in adult population presenting with an age range of 13 to 59 years (72\%). Overall number of GI endoscopic biopsies in paediatric group $(<12 \%)$ was less comparatively. The age related difference could be due to the variation in risk factors among different age groups. Since the probability of malignancy increases with ad- 


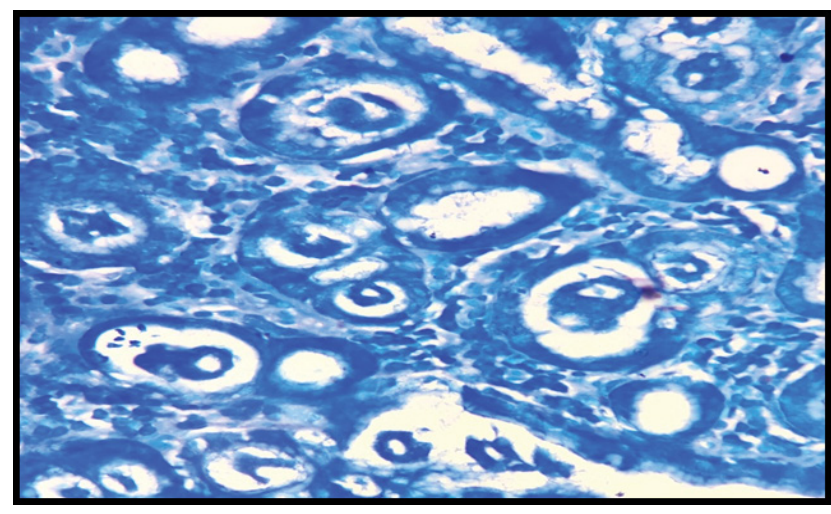

Figure 5b: H. Pylori gastritis (Giemsa stain).

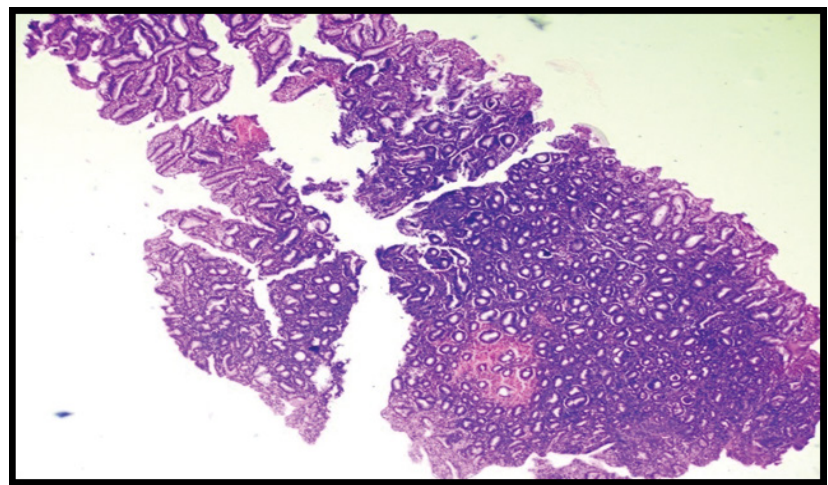

Figure 6: Atrophic gastritis ( $\mathrm{H} \mathrm{n} \mathrm{E)}$.

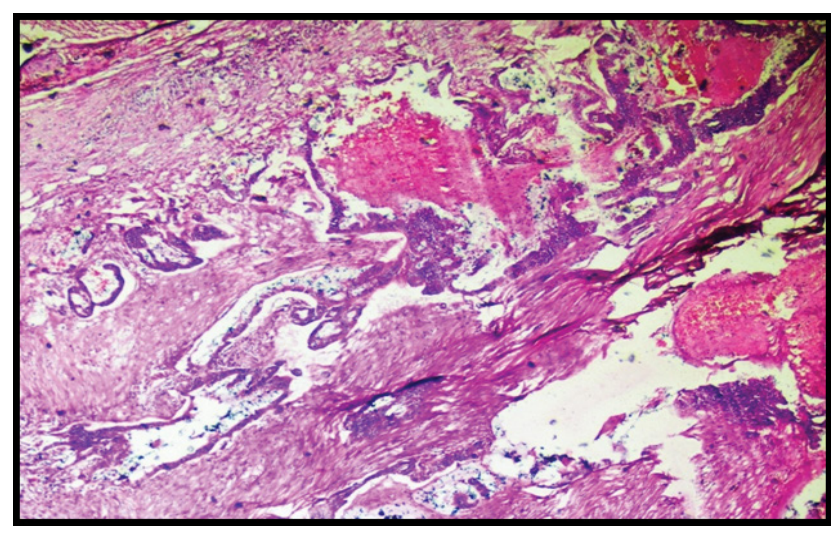

Figure 7: Adenocarcinoma lleum (H\&E).

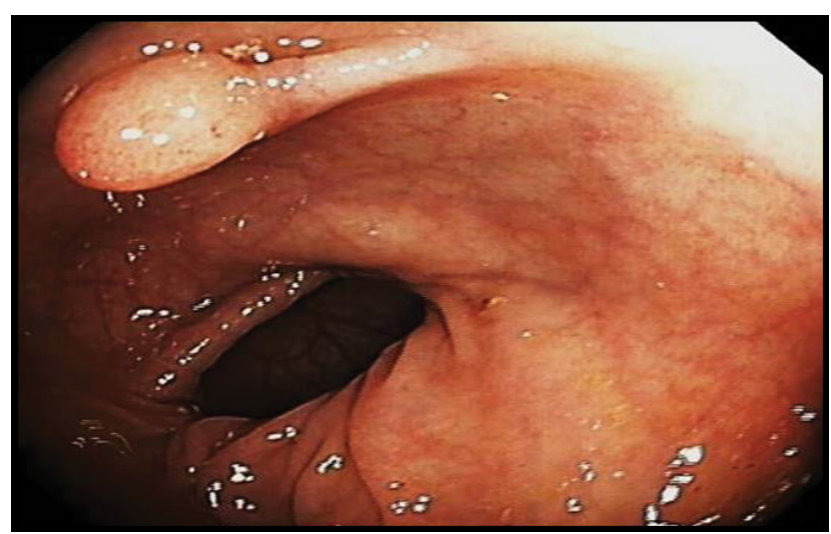

Figure 8a: Rectal polyp (endoscopy image).

vancing age, all the suspicious lesions on endoscopy are subjected to biopsy for histopathological analysis.

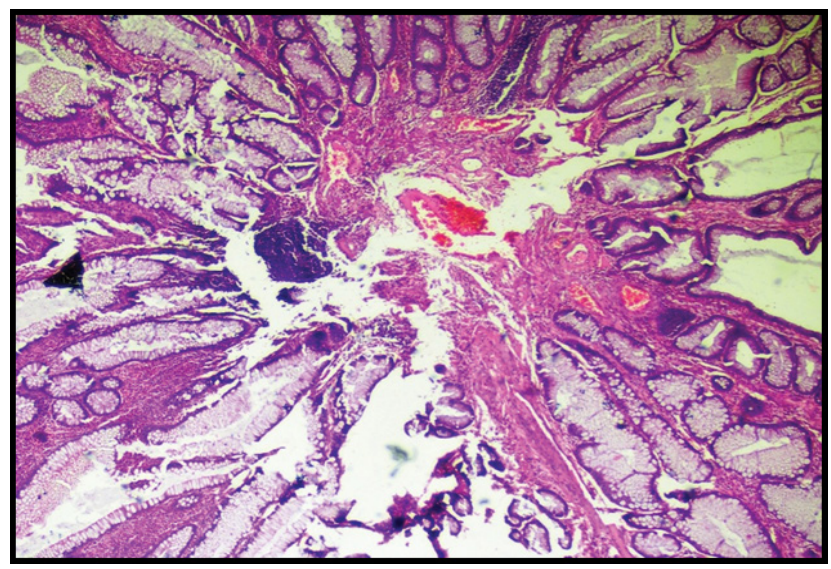

Figure 8a: Rectal polyp (H\&E).

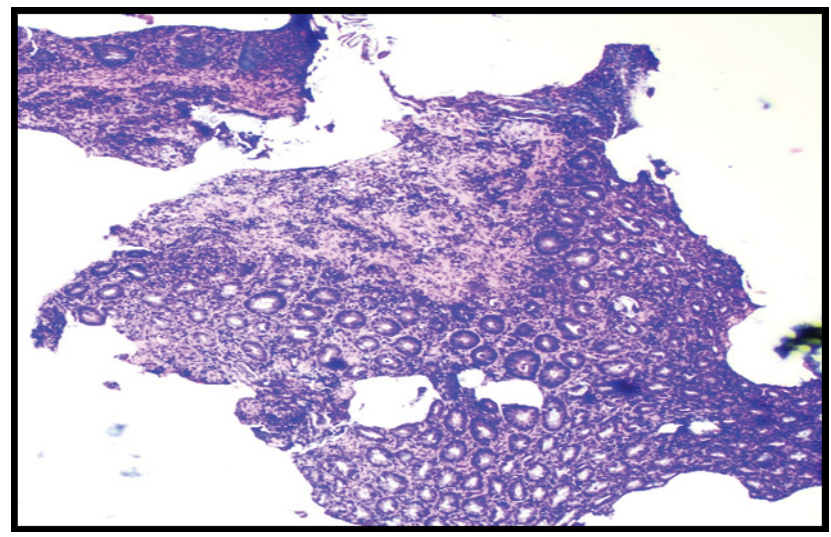

Figure 9: Proctitis (H\&E).

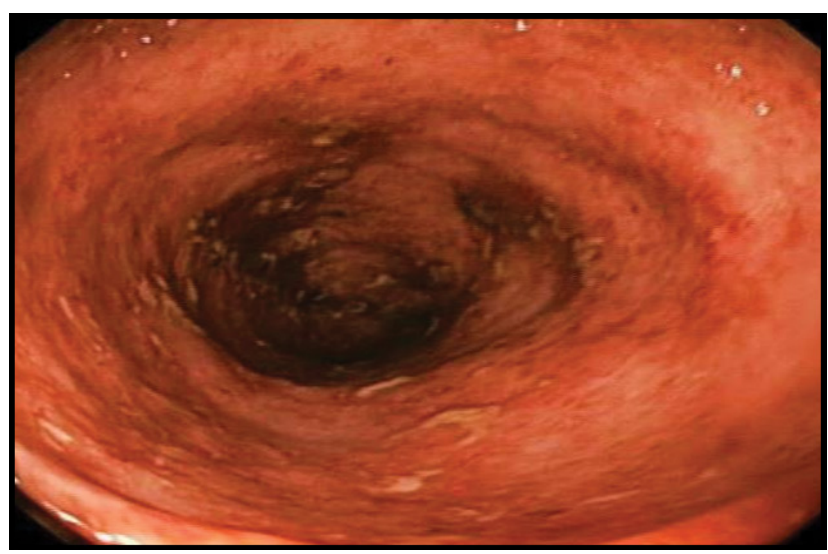

Figure 10a: Ulcerative colitis (endoscopy image).

These findings are in concordance with the study conducted by Rashmi, et al. [3], Abilash SC, et al. [4], and Ganga, et al. [5] where majority of GI lesions were in $4^{\text {th }}$ and $5^{\text {th }}$ decade.

In the present study, male preponderance was recorded in all age-groups with male to female ratio being 1.4:1, 1.5:1 and 1.6:1 respectively in paediatric, adult and geriatric group. A male predisposition for $\mathrm{GI}$ lesions has been a consistent finding of various studies conducted in different parts of the country. A clear cut male predominance was observed in studies conducted by Hussain, et al. [6], Rashmi, et al. [3] and Ganga, et al. 


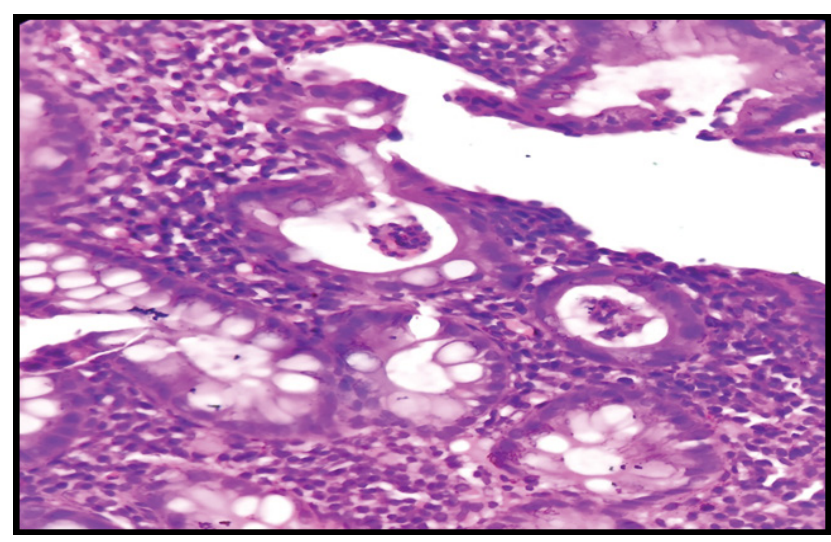

Figure 10b: Ulcerative colitis (H\&E).

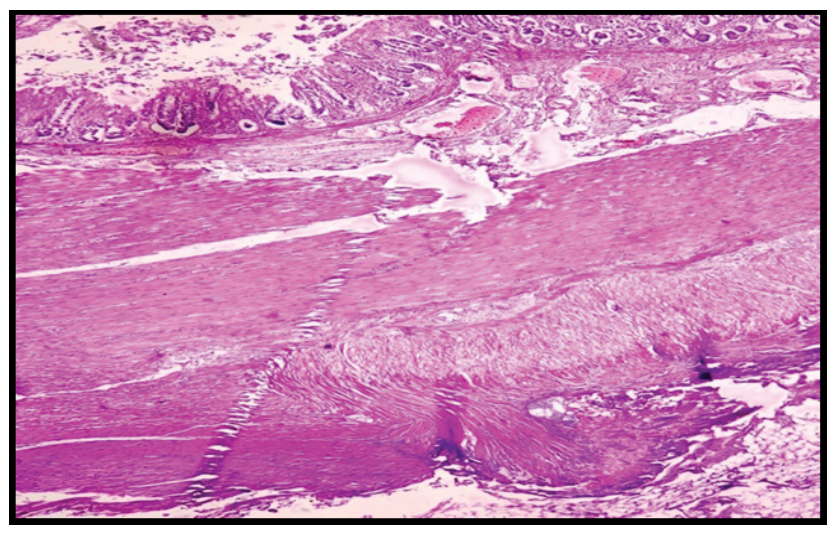

Figure 11: Hirschsprung disease (H\&E).

Table 7: Correlation of clinical, endoscopic and histopathological diagnosis.

\begin{tabular}{|c|c|c|c|}
\hline Site & Clinical Diagnosis & Endoscopic Diagnosis & Histopathological Diagnosis \\
\hline \multirow[t]{4}{*}{ Esophagus } & Carcinoma Esophagus & Growth with ulceration & Squamous cell carcinoma \\
\hline & Esophagitis & Normal findings & Non-specific Inflammation \\
\hline & Esophagitis & Erythema & $\begin{array}{l}\text { Gastro-oesophageal reflux disease } \\
\text { (GERD) }\end{array}$ \\
\hline & Carcinoma Esophagus & Growth & Adeno-squamous carcinoma \\
\hline \multirow[t]{5}{*}{ Stomach } & Carcinoma Stomach & Ulcerating fungating growth & Adenocarcinoma \\
\hline & ?GIST & Growth & GIST \\
\hline & Gastritis & Erosion & Non-specific Inflammation \\
\hline & Gastritis & Ulcer & H. Pylori induced gastritis \\
\hline & Gastritis ?Autoimmune & Erythema and Erosion & Chronic atrophic gastritis \\
\hline \multirow[t]{3}{*}{ Duodenum } & ?Celiac Disease & Scalloped mucosa & Celiac Disease \\
\hline & Duodenitis & Erythema & Non-specific inflammation \\
\hline & Duodenitis & Ulcer & Duodenal ulcer \\
\hline \multirow[t]{2}{*}{ Ileum } & $\begin{array}{l}\text { ?IBD (Inflammatory Bowel } \\
\text { Disease) }\end{array}$ & Erythema & Non-specific inflammation \\
\hline & Carcinoma & Ulcerated bleeding mass & Adeno-carcinoma \\
\hline \multirow[t]{3}{*}{ Colon } & Colon Polyp/Mass & Polyp & Tubular Adenoma \\
\hline & Follow-up case of resection colon & Normal colonoscopic findings & Non-specific inflammation \\
\hline & Colitis & Normal mucosa & Lymphocytic colitis \\
\hline \multirow[t]{5}{*}{ Rectum } & Rectal polyp/ growth & Growth & Rectal polyp \\
\hline & Proctitis & Edematous mucosa & Chronic proctitis \\
\hline & ? IBD & Irregular mucosa & IBD \\
\hline & Ulcer & Hyperemic mucosa & Solitary rectal ulcer \\
\hline & ?Hirschsprung disease & Normal & Hirschsprung disease \\
\hline
\end{tabular}

[5] who reported male to female ratio of 2.8:1, 2.03:1 and 1.57:1 respectively. This male predisposition maybe because males are more exposed to risk factors in comparison to females.

In the present study, incidence of upper GI endoscopic biopsies was higher than lower GI endoscopic biopsies in all the age groups. The findings of our study correlated with the observations of Rashmi, et al. [3]. They also reported predominance of upper GI lesions on endoscopic biopsies, with $27 \%$ lesions occuring in $5^{\text {th }}$ and $6^{\text {th }}$ decade.
In our study, benign lesions outnumbered the malignant lesions in all age-groups. Out of 65 endoscopic biopsies in paediatric population, 64 biopsies (98\%) were benign. Similarly, in adults and geriatric group $76 \%$ and $61 \%$ biopsies were benign respectively. Rashmi, et al. [3] documented similar findings. They reported the incidence of benign esophageal lesions to be $56 \%$ and that of malignant lesions to be $44 \%$. They also reported higher incidence of benign gastric lesions (60\%) than malignant lesions (40\%). Our observations were again in conformity with the findings of Ganga, et al. [5] where majority of lesions were non-neoplastic. 
In this study, stomach was the most common site of biopsy followed by duodenum in the adult group. While in geriatric population, esophageal biopsies were more commonly seen. Our findings were concordant with the study done by Ganga, et al. [5] in which most common site of endoscopic biopsy was stomach followed by duodenum and esophagus. Venkatesh, et al. [2] also reported gastric biopsies to be most common ( $57 \%$ of total 180) GI biopsies. This is similar to study done by Prasad PR [7] and Bilal, et al. [8] who observed gastric biopsies to be most common biopsy received accounting for $56 \%$ and $64.8 \%$ of total GI biopsies. In our study, among lower GI biopsies rectal biopsy was most common in all age-groups. Venkatesh, et al. [2] showed colon to be the most common site of lower GI biopsies, this finding was discordant with our study.

In the present study, most common lesion in esophagus was squamous cell carcinoma mainly affecting adult age-group followed by geriatric group. The other malignant neoplasm encountered was Adeno-squamous carcinoma. Our findings are in conformity with the study done by Rashmi, et al. [3], Mchembe, et al. [9], Abilash SC, et al. [4] and Shanmugaswamy, et al. [10]. Among non-neoplastic lesions, non-specific inflammation was most common which is similar to the findings by Ganga, et al. [5].

In this study, among gastric biopsies non-neoplastic lesions were common than neoplastic lesions. Out of 190 gastric biopsies in adults, 183 were non-neoplastic and in geriatric group 18 out of 22 biopsies were non-neoplastic. Ganga, et al. reported similar findings, out of 93 gastric biopsies 68 were inflammatory lesions [5]. Among the non-neoplastic lesions (183 cases), highest number of cases fell under the group of non-specific inflammation (105 cases). Similar observations were made by Somani, et al. [11] (40\%), Rashmi, et al. [3] (37\%). H. Pylori induced gastritis was next most frequently encountered inflammatory lesion in our study, accounting for $14 \%$ of all gastric lesions in adults and $6 \%$ in elderly patients. In the current study, we didn't encounter any case of gastric ulcer on endoscopic biopsy. This maybe because most of the patients presenting with symptoms suggestive of gastric ulcer were treated either directly without conforming diagnosis with endoscopy or after performing urea breath test to detect H. pylori.

In the present study, we found all the cases of gastric malignancy as Adenocarcinoma. No malignancy was seen in paediatric group. These observations are again in conformity with the findings of Shiva, et al. [12], Rashmi, et al. [3] and Bilal, et al. [8] who reported adenocarcinoma as most common gastric malignancy. 7 cases of GIST were also reported in our study (4 in adults, 2 in elderly and 1 in paediatric group).

In our study, most common lesion on duodenal biopsy in adults was non-specific inflammation followed by duodenal ulcer. While in paediatric group, celiac disease was commonly encountered. No malignancy was reported in the study. These findings are similar to those of Venkatesh, et al. [2].

The lower GI lesions in present study showed a variable spectrum comprising of non-neoplastic, benign and malignant lesions. Adenocarcinoma was most only malignancy encountered in lleum. Most common lesion on colonic biopsy in adults was lymphocytic colitis followed by non-specific colitis. 4 cases of Tubular adenoma ( 2 each in adults and elderly group) were also seen. Ventakesh, et al. reported non-specific colitis as commonest lesion on colon biopsy [2], this finding was discordant with our study.

Among the paediatric group, out of 20 rectal biopsies rectal polyp 13 (20\%) was most common diagnosis. 2 cases of Hirschsprung disease and 1 case of Solitary rectal ulcer was also detected in our study. Inflammatory bowel disease was most common diagnosis in adults contributing 7 out of total 18 cases. In a study conducted by Al Brahim, et al. rectal ulceration was most common finding followed by rectal polyps [13].

In this study, most of the histologically confirmed cases of malignancy were either reported as simple growth or ulcerative growth, some also presented as mucosal thickening. This is in concordance with the findings of Somani, et al. who reported growth and mucosal thickening as most common endoscopic finding in malignant lesions [11]. In a study by Rashmi, et al. $90 \%$ lesions endoscopically detected as growth turned out malignant [3]. Polyps and Adenomas also presented as growth. Most of non-neoplastic lesions either presented as erythema or as ulcerated mucosal lining.

\section{Conclusion}

In our study, a variety of non-neoplastic and neoplastic lesions were studied. Out of $556 \mathrm{Gl}$ endoscopic biopsies, maximum numbers of cases were detected in adult age group. Duodenal biopsies were more frequent in paediatric group, with celiac disease being most common diagnosis. In adults, gastric biopsies were maximum, most common being non-specific inflammation. In geriatric group, maximum were esophageal biopsies with squamous cell carcinoma as most common diagnostic entity.

Due to tiny biopsy material limitations in diagnostic interpretation are often encountered. Multiple biopsies from abnormal appearing mucosa on endoscopy may aid with definitive diagnosis and also reduces chances of error. In case of dubious lesions, biopsy results served to correct mistaken endoscopic findings. Hence, we concluded that endoscopy in combination with biopsy is a powerful diagnostic tool in detecting as well monitoring disease course and patient outcome. In addition, it has the advantage of being cost-effective and can be incorporated easily in routine diagnostic protocols. 


\section{Acknowledgement}

Nil.

\section{Conflict of Interest}

Nil.

\section{References}

1. Bray F, Ferlay J, Soerjomataram I, Rebecca L Siegel, Lindsey A Torre, et al. (2018) Global cancer statistics 2018: GLOBOCAN estimates of incidence and mortality worldwide for 36 cancers in 185 countries. CA Cancer J Clin 68: 394-424.

2. Venkatesh V, Thaj RR (2019) Histopathological spectrum of lesions in gastrointestinal endoscopic biopsies: A retrospective study in a tertiary care center. World Journal of Pathology 8: 1-6.

3. Rashmi K, Horakerappa MS, Karar A, Mangala G (2013) A study on histopathological spectrum of upper gastrointestinal tract endoscopic biopsies. Int J Med Res Health Sci 2: 418-424.

4. Abilash S, Kolakkadan H, MM G, Shreelakshmidevi S, Balamuruganvelu S (2016) Histopathologic spectrum of upper gastrointestinal tract mucosal biopsies: A retrospective study. Sch J Appl Med Sci 4: 1807-1813.

5. Ganga H, Indudhara PB (2018) Histopathological spectrum of lesions of upper gastrointestinal tract: A study of endoscopic biopsies. International Journal of Clinical and Diagnostic Pathology 1: 21-25.
6. Hussain SI, Reshi R, Akhter G, Beigh A (2015) Clinico histopathological study of upper gastrointestinal tract endoscopic biopsies. IJCRR 7: 78-85.

7. Prasaad PR, Rao B (2016) Histopathological spectrum of gastrointestinal lesions - an experience in a tertiary care centre in South India. Int J Res Med Sci 4: 3407-3412.

8. Bilal A Sheik, Shaista M Hamdani (2015) Histopathological spectrum of lesions of upper gastrointestinal tract. Global Journal of Medicine and Public Health 4.

9. Mchembe MD, Rambau PF, Chalya PL, Jaka H, Koy M, et al. (2013) Endoscopic and clinicopathological patterns of esophageal cancer in Tanzania: Experiences from two tertiary health institutions. World J Surg Oncol 11: 257.

10. Shanmugasamy K, Bhavani K, K AV, Narashiman R, Kotasthane DS (2016) Clinical correlation of upper gastrointestinal endoscopic biopsies with histopathological findings and to study the histopathological profile of various neoplastic and non-neoplastic lesions. J Pharm Biomed Sci 6: 220-224.

11. Somani NS, Patil P (2018) Histopathological study of the upper gastrointestinal tract endoscopic biopsies. Annals of Pathology Laboratory Medicine 5: 683-688.

12. Shiva Raj K, Amatya G, Lakhey A, Basnet S, Aryal G (2013) Incidence of gastric cancer, its subtypes, and correlation with Helicobacter Pylori. J Pathol Nepal 3: 403-407.

13. Al-Brahim N, Al-Awadhi N, Al-Enezi S, Alsurayei S, Ahmad M (2009) Solitary rectal ulcer syndrome: A clinicopathological study of 13 cases. Saudi Journal of Gastroenterology 15: 188-192. 